\section{Desospitalização e cuidados paliativos domiciliares no Sistema Único de Saúde brasileiro}

\section{Wiegand, B. B.}

Mestranda do Programa de Pós-graduação em Bioética da Pontifícia Universidade Católica do Paraná (PUC-PR). barbarabowoniuk@hotmail.com.

Meirelles, J. M. L.

Doutora em Direito das Relações Sociais. Professora do Programa de Pós-graduação em Bioética da Pontifícia Universidade Católica do Paraná (PUC-PR).

PALAVRAS CHAVE: Desospitalização; cuidados paliativos; Sistema Único de Saúde.

Introdução: a abordagem dos cuidados paliativos cresce no Brasil, à medida em que as discussões sociais sobre o assunto fim de vida se tornam mais efetivas. Dessa forma, os serviços de atenção domiciliar são oferecidos pelo Sistema Único de Saúde (SUS), ao levar atendimento de equipes multiprofissionais para continuidade dos cuidados hospitalares na residência do paciente, de forma integrada com a Rede de Atenção à Saúde. Método: a pesquisa proposta tem como fundamento a análise das políticas públicas brasileiras voltadas para a atenção domiciliar e cuidados paliativos. Trata-se de revisão de Portarias do Ministério da Saúde, programas do governo e outras normas que regulamentem o assunto. Resultados: notou-se no âmbito do SUS o programa "Melhor em casa" [1], que presta o Serviço de Atendimento Domiciliar (SAD). Com o atendimento em domicílio, busca-se ofertar um serviço humanizado e próximo dos familiares, evitam-se hospitalizações desnecessárias, além da diminuição do risco de infecções. A desocupação dos leitos hospitalares é outro reflexo que colabora para busca pela regulação dos serviços fora dos hospitais. Além disso, a portaria $\mathrm{n}^{\circ} 3535 / 1998$ do Ministério da Saúde [2], estabelece os critérios para cadastramento de centros de atendimento em oncologia, que deverão prestar serviço de cuidados paliativos em ámbito domiciliar. Ademais, a portaria elenca que devem ser oferecidas: assistência multiprofissional, garantia de internações por intercorrência e de longa permanência, bem como medicação ou procedimentos para controle da dor. Ainda é possível destacar a Resolução do Conselho Federal de Medicina (CFM) de ${ }^{\circ}$ 2.156/2016 [3], que estabelece os critérios para indicação de admissão ou de alta para pacientes em Unidade de Terapia Intensiva (UTI). A Resolução recomenda os cuidados paliativos para os pacientes em fase de terminalidade ou sem possibilidade de recuperação. A oferta de cuidados deve levar em conta a vontade expressa do paciente ou de seu representante legal, além de evitar ações diagnósticas ou terapêuticas inúteis ou obstinadas. Conclusões: muito embora seja uma realidade no SUS, é preciso considerar que o atendimento domiciliar impõe aos familiares e cuidadores preparo e capacitação, num momento em que a familia se encontra fragilizada em razão da doença do paciente. As limitações do SUS são verificadas na prática tantas pelas equipes de saúde, quanto pelos pacientes e familiares. Sendo assim, uma Política em âmbito Nacional efetiva e o assessoramento do Ministério da Saúde para cuidados paliativos poderão contribuir para a redução das vulnerabilidades dos pacientes em cuidados paliativos e seus familiares no momento da desospitalização, almejando-se garantir o direito à saúde e a qualidade no fim de vida.

AGRADECIMENTOS: $O$ presente trabalho foi realizado com apoio da Coordenação de Aperfeiçoamento de Pessoal de Nível Superior - Brasil (CAPES) - Código de Financiamento 001.

\section{REFERÊNCIAS}

[1] BRASIL. Ministério da Saúde. Secretaria de Atenção à Saúde. Departamento de Atenção Básica. Caderno de atenção domiciliar. Brasília (2013).

[2] BRASIL. Portaria $\mathrm{n}^{\circ}$ 3.535, de 2 de setembro de 1998. Estabelece critérios para cadastramento de centros de atendimento em oncologia. Brasília (1998).

[3] BRASIL. Conselho Federal de Medicina (CFM). Resolução $n^{\circ}$ 2.156/2016. Estabelece os critérios de admissão e alta em unidade de terapia intensiva. Brasília (2016). 